\title{
Allied health professional rural education: Stellenbosch University learners' experiences
}

\author{
M Pillay, ${ }^{1}$ MSpPath, DEd; J Bester, ${ }^{2}$ MPhil; R Blaauw, ${ }^{3}$ MNutr, PhD (Nutr); A Harper, ${ }^{3}$ MSc (Clin Epi); A Msindwana, ${ }^{4}$ BSpLangHearTh; \\ J Muller, ${ }^{5}$ MSc (Physio); L Philips, ${ }^{3}$ BSc Diet \\ ${ }^{1}$ Division of Speech-Language and Hearing Therapy, Interdisciplinary Health Sciences, Faculty of Medicine and Health Sciences, Stellenbosch University, Cape Town, South Africa (currently: \\ Discipline of Speech-Language Pathology, School of Health Sciences, University of KwaZulu-Natal, Durban, South Africa) \\ ${ }^{2}$ Division of Occupational Therapy, Interdisciplinary Health Sciences, Faculty of Medicine and Health Sciences, Stellenbosch University, Cape Town, South Africa \\ ${ }^{3}$ Division of Human Nutrition, Interdisciplinary Health Sciences, Faculty of Medicine and Health Sciences, Stellenbosch University, Cape Town, South Africa \\ ${ }^{4}$ Division of Speech-Language and Hearing Therapy, Interdisciplinary Health Sciences, Faculty of Medicine and Health Sciences, Stellenbosch University, Cape Town, South Africa \\ ${ }^{5}$ Allied Health Sciences: uKwanda Centre for Rural Health, Faculty of Medicine and Health Sciences, Stellenbosch University, Cape Town, South Africa
}

Corresponding author: M Pillay (pillaym1@ukzn.ac.za)

Background. Rural clinical training is not widely established or documented for allied health sciences (AHS) learners. This article focuses on the experiences of AHS learners from Stellenbosch University's uKwanda Rural Clinical School.

Objective. To explore learners' practices with regard to rural clinical training in the AHS.

Methods. A total of 22 documented reflections and seven educator or learner semi-structured focus group discussions, using critical conversations, were analysed with methods such as textual and thematic analysis and qualitative research software (ATLAS.ti, Germany).

Results. The perception of rural clinical training was reported as an overwhelmingly positive experience. Practices positioned 'rural' as a catalyst for developing learners' emerging identities as policy brokers, and as best when delivered by team participation. Professional education curricula were reported as dependant on: (i) context; (ii) educators; and (iii) how time was managed.

Conclusion. Rural-based learning is a humanising experience for health science learners.

Afr J Health Professions Educ 2016;8(2):169-173. DOI:10.7196/AJHPE.2016.v8i2.578

Rural clinical training is not a new concept, especially for medical doctors, and is a global phenomenon. In South Africa (SA), the earliest account of medical rural training was the Pholela Health Centre, started in KwaZulu-Natal (KZN) in the 1940s. ${ }^{[1]}$ Later, in 1992, KZN tertiary educators pioneered multidisciplinary, rural clinical education for various allied health sciences (AHS) disciplines ${ }^{[2]}$ along with medical and nursing education. SA has a history of an urban service bias, with $12 \%$ of SA's medical practitioners, $19 \%$ of nurses ${ }^{[3]}$ and an unrecorded, but possibly small percentage of AHS practitioners being rural based. ${ }^{[4]}$ The advent of compulsory community service inspired the development of Stellenbosch University's uKwanda Rural Clinical School, which began training medical doctors in 2011. ${ }^{[5]}$ Training broadened from 2012 onwards to include final-year learners from AHS and included Human Nutrition (HN), Physiotherapy (PT), Speech-Language Therapy (SLT) and Occupational Therapy (OT). Rotations include clinical blocks and/or 1-year placements for students of some of the disciplines at rural sites and for others at urban sites. On average, 44 of 100 Stellenbosch University AHS students experienced the uKwanda Rural Clinical School training platform during their final year of training. We hope to increase the number in future. As this is a relatively new learning site, we are curious about what, or more specifically how, our learners experience practice changes, i.e. from urbanbased, individualised care and/or traditional medical training sites to the more rural-based clinical training.

In this study, the Curriculum of Practice (Fig. 1), ${ }^{[6]}$ a conceptual framework, was used to situate learners' practice experiences, the components of which include (i) clinical practices (and associated resources); (ii) professional educational curricular policies; and (iii) practice policies.

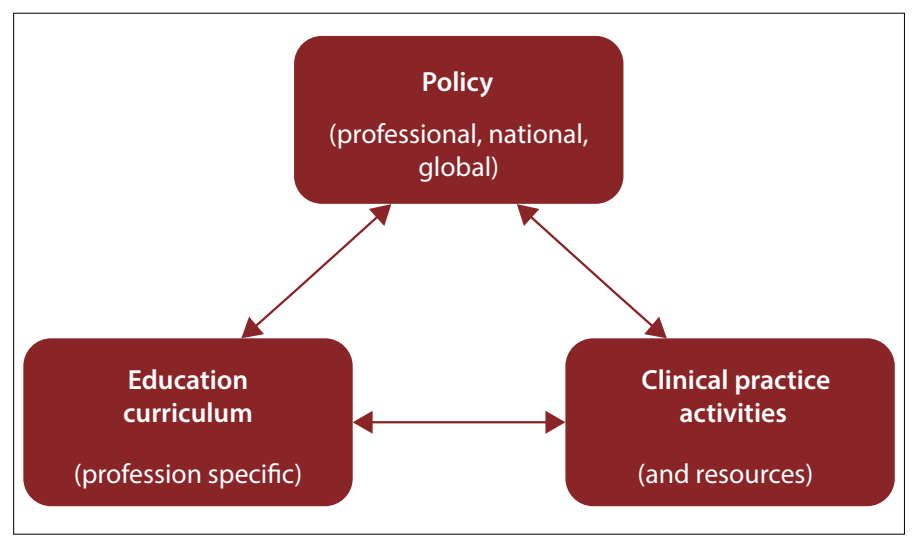

Fig. 1. Curriculum of Practice, adapted from Pillay $M$, et al. ${ }^{[4]}$

Practice is promoted as integrally connected to theory, policy and factors such as clinical resources - and not as abstract, decontextualised things that we do. ${ }^{[7]}$ Clinical practice activities are understood relative to what learners are taught in their professional curricula. For example, the manner in which a child with cerebral palsy eats, may, for an occupational therapist, mean focusing on the mealtime as an activity of daily living. However, a speech therapist will assess 'feeding/swallowing abilities'. They are also guided by best practice local and/or national or international guidelines from organisations such as the World Health Organization. Hence, policy interacts with practice.

Clinical practice also comprises available resources. What happens when we have no standardised tests for isiXhosa speakers? Or, how does one begin 
to assess what disability means in the context of abject poverty? Therefore, practices are dependent on human, physical, financial and conceptual and/or social capital. Our responses or actions to realities such as resource constraints interact with our world views, e.g. of cultural-linguistic, social, gender, racial and political values. Therefore, to develop what we consider to be good practice, we can use standardised, norm-based diagnostic tools. This satisfies our need to be objective and scientific and promote technically sound, rational ways of thinking about the world. However, when faced with practice dilemmas, what values do we follow? In the Curriculum of Practice, we promote an analysis of what is regarded as truth (or what is known) to engage practice that positions our knowledge with regard to professional education curricular and practice policies.

\section{Objective}

The critical question posed was: how do Stellenbosch University's AHS students experience practice in a rural clinical training site? Therefore, the objective was to explore learners' practice experiences with regard to rural clinical training in the AHS context.

\section{Methods}

This exploratory study design allowed us to describe how our experience, insight and skills are incorporated to propose new and innovative ways of understanding and interpreting reality. ${ }^{[8]}$ Data were collected at the end of the 2013 clinical placement, using conduct sheets for documented data, video-recorded or written reflections (video journals or written reflective diaries), and educator and learner focus group discussions (FGDs). A method focusing on the use of discourse techniques for AHS professional development, ${ }^{[9]}$ i.e. critical conversations, was used during semi-structured group discussions. This method of critical conversations is intended to challenge participants' political, cultural and related notions, e.g. gender, race and class, with the interviewers asking questions such as 'What about your identities in relation to those of your participants, e.g. white, middleclass South Africans working with coloured farm labourers?'

All verbal data were transcribed, with English translations of Afrikaans data being double blind, back translated. Data were cleaned for unnecessary irregularities and broken text, syntactic redundancies or illegible text. All data were tagged per word or sentence and labelled accordingly before being thematically analysed by two research assistants not attached to the study. Qualitative data software (ATLAS.ti, Germany) was used to perform data coding, categorisation and thematic analysis. Data were reviewed by the study sub-investigators, who functioned as a reference group. Member checks involved participants' review of edited transcripts and investigators' interpretations of data. A final report was circulated to participants from the office of the deputy dean of Community Service and Interaction, Stellenbosch University.

Ethical approval for this study was obtained from Stellenbosch University's Health Research Ethics Committee (ref. no. N13/10/134).

\section{Sample}

Data sources included final-year learners $(N=44)$ and educators $(N=8)$. These learners represented the total number of learners who completed their rural training rotation. Rotations vary between 6 weeks and a full clinical year. Study participants were included if they were associated with any of the rural uKwanda sites (Worcester, Stellenbosch, Ceres, Hermanus) from 2011 to 2013. Data included 22 sets of learners' video-recorded or written reflections, one unidisciplinary (human nutrition) and two multidisciplinary educator FGDs, and four learner FGDs, one for each discipline.

\section{Results}

A total of 131 coded categories were clustered and analysed. Perceptions of rural clinical practice were assessed, using the Curriculum of Practice, resulting in the following key themes:

- 'uKwanda-ful': the perception of rural clinical training as an overwhelmingly positive experience

- rural clinical training as a catalyst for developing learners' emerging identities as policy advisors

- professional practices are best when delivered by team participation

- data about professional educational curricula centred around three core themes, i.e. (i) context; (ii) educators; and (iii) time.

\section{uKwanda-ful: The perception of rural clinical training as an overwhelmingly positive experience}

'We called it an uKwanda-ful experience.' (PT, FGD, Learner 3)

uKwanda-ful, a neologism created from wonderful and uKwanda, was a theme that resonated across data sets and was possible because of a nexus of: (i) relationships between learners and educators or uKwanda staff; (ii) relationships with the community; and (iii) sense of self. Many learners linked their perceptions of staff to the workspace or environment (Table 1).

Table 1. Extracted data highlighting learner-educator relationships

\begin{tabular}{llll}
\hline Code data category & Example & Source \\
\hline $\begin{array}{l}\text { Passionate and } \\
\text { enthusiastic staff }\end{array}$ & 'The people in Worcester want to teach you. They're very centred around getting you passionate about your field.' & OT Learner, FGD \\
$\begin{array}{l}\text { More structural and } \\
\text { emotional support }\end{array}$ & $\begin{array}{l}\text { '... but it was also a lot more emotional, as you are working in the community and you see bad situations.' } \\
\text { 'These co-ordinators would send us out into the community ... we know they are there for support .... }\end{array}$ & OT Learner, FGD \\
$\begin{array}{l}\text { More informal and } \\
\text { relaxed atmosphere }\end{array}$ & 'It's much more relaxed, the atmosphere is more relaxed.' & ST Learner, FGD \\
$\begin{array}{l}\text { Friendliness among } \\
\text { the disciplines }\end{array}$ & $\begin{array}{l}\text { 'They're talkative and friendly and they don't turn you away. They help you, and try to help you get to the answer } \\
\text { of something if they don't know themselves. And especially with .... the OTs, physios, dieticians, we walk past them } \\
\text { but we always greet each other. The same with the cleaners.' }\end{array}$ & OT Learner, FGD
\end{tabular}


The key enablers for this positive experience included: (i) educators' faith in learners' abilities; (ii) educators' treatment of learners as equals and colleagues; (iii) a supportive and stimulating approach; and (iv) educators' facilitation of learners' sense of independence. Notably, only one learner referred to a negative experience with clinical training staff, a relationship that was mended and reported as being overshadowed by the entire uKwanda experience. Another significant relationship was with the community, as stated, below (Table 2):

'I think for me, it's the becoming part of the community thing ... to know what's going on in their lives. You cannot actually treat a patient properly without knowing what's going on. I really enjoyed that, getting to know them and seeing how you can make a different in their lives, so that it's actually meaningful.' (SLT 1, FGD)

Learners associated their value with: (i) community appreciation of their work; (ii) value of home visits and seeing patients in their environment; and (iii) opportunity to follow up patients. Importantly, the relationship with the community was not always easy to manage given the magnitude of the latter's socioeconomic circumstances, such as access to food, highlighted below:

'I was happy, proud of the mom for taking a stand and do what was right - look after her baby. I felt comfortable because for the first 6 months of

Table 2. Data extracts to illustrate significant results

\begin{tabular}{l} 
Number $\quad$ Data extract \\
\hline 1 \\
'I think for me, it's the becoming part of the community thing ... to know what's going on in their lives. You cannot actually \\
treat a patient properly without knowing what's going on. That's the wonderful part about the rural setting for me. I really \\
enjoyed that, getting to know them and seeing how you can make a different in their lives, so that it's actually meaningful.' \\
'I was happy, proud of the mom for taking a stand and do what was right - look after her baby. I felt comfortable because for \\
the first 6 months of her life, she would have food (breastmilk) which was sufficient for her. But after the 6 months, \\
then what? That just really saddened me and I felt so helpless. I wish I could have done more.' \\
'I really experienced that use of freedom, which I didn't see in previous years. For example, they took chances, showed
\end{tabular}
initiative, they tried new things. 'I hated the fact that I had so many fears, I just wanted to let it go and just "be" ... ? '... in the hospital or the rehab clinic, you didn't have the same freedom.'

'There is a guy in a wheelchair and he is very floppy in his wheelchair, but in the rural area, there are potholes everywhere. The RDP houses, they have steps [shows with hands] to go into the house and you can't do that with a wheelchair. And that is the community for whom the RDP houses were built.'

'... all of us got together and had a braai and this is now our clinical co-ordinators, the therapists from the hospital and the areas that we work, and once again that just reinforces the team and the family. It's not just that you're a student, you really are a team ... we were like 15 or 20 people at the braai. We all sat together and talked about other things than occupational therapy' '... the different disciplines that were there ... it wasn't just speech therapists together. It was better as we could see what the physio's outlook on things was, as well as what they can do from their side or change. It's not just your perspective, but a whole group of other perspectives, and how to incorporate what you do together with other's professional disciplines.'

9 'The overall goal of a hospital is to get people out as soon as possible, so you're sort of working against time, a clock ... whereas in a community, you go in and you don't really have this entire electronic system ... where you can just type in a few details and it brings up everything that has happened, or this referral has been made. Things like that happen. In the community ... you have to see what is most needed at this stage and start there. First you do "damage control", if I can call it that, then from there, you set a structure in place for the next person to come in. You're building something, it's not already there for you to just use.'

'That's the wonderful part about the rural setting for me. I really enjoyed that, getting to know them and seeing how you can make a difference in their lives, so that it's actually meaningful. I went to X school every evening and read to the children. The 3 - 6-year-olds are there for 3 months, they don't really see anyone that is a significant person to them, and I sort of wanted to give that to them. I had no idea I was going to do this, but I sort of learnt from the kids. It didn't make sense at all to just go in there every day, but once you actually got into it you realise what you're supposed to do.' '... because the needs, and the facilities ... the resources are totally different. They require you to think differently ... So you become more than just a speech therapist. That's what I think the students also acquire; they become more than a physio, they become a social worker, a counsellor, a psychologist, a fund-raiser. They become advocates.'

Student 8: 'Something else that also stood out for me, compared with (names of three urban-based hospitals in the Cape

Participant

ST, Learner 1, FGD

HN, Learner 1

OT, Learner 2

HN, Learner 1

ST, Learner 4, FGD

OT, Learner 1

OT, Learner 5

ST, Learner 3, FGD

ST, Learner 8, FGD

ST, Learner 1, FGD Metropole), the people in Worcester want to teach you. They're very centred around getting you passionate about your field.' Interviewer: 'By people, do you mean therapists or other staff?'

Student 8: 'Not just the therapists. Not only our clinical co-ordinators, but also, for example, the people who are not OTs, such as the physiotherapy co-ordinator.'

Interviewer: 'So anyone?'

Student 8: 'Anyone who works for uKwanda.'

Student 3: 'Not always the doctors ... .' [Students laugh] 
[baby's name] life, she would have food (breastmilk), which was sufficient for her. But after the 6 months, then what? That just really saddened me and I felt so helpless. I wish I could have done more.' (HN, Learner 1)

Feelings, e.g. of helplessness, are closely linked to learners' sense of self. As part of this construction of learners' identities (as rural clinical practitioners), many reported a sense of freedom:

'I really experienced that use of freedom, which I didn't see in previous years. For example, they [learners] took chances, showed initiative, they tried new things.' (OT, Educator 3 )

'... in the hospital or the rehab clinic, you didn't have the same freedom. (SLT 4, FGD)

In spite of the overwhelming positive experience, several barriers with regard to the development of this sense of self were identified, including several psycho-emotional areas, such as learners not feeling confident about building a relationship with staff. Some learners and educators reported feeling as though the rural clinical block was 'at their expense', reporting that '... in the first two weeks, it was very negative and they felt completely out of control, and out of their depth'. (Multidisciplinary team (MDT), FGD, Respondent 2)

Learners faced difficulties with issues of language, culture, lack of appropriate clinical resources and not knowing how to deal with poverty and associated practice issues (detailed below in the sections on practice). In contextualising this data set, we found it useful to position an analysis of a learner (from $\mathrm{HN}$ ) and her personal experiences while based at one of the training sites (Ceres) (Table 3).

\section{Rural clinical training as a catalyst for developing learners' emerging identities as policy advisors}

In the multidisciplinary group discussion, uKwanda was positioned as a product of post-apartheid SA, aligned with ideologies from government policy such as social justice and equity. An emerging factor is that rural clinical training is a catalyst for learners' development as policy brokers not merely policy implementers. Clinical educators facilitate learners' need to be '.. aware of systemic problems ... to more government or state issues that influence their training. (MDT, FGD, Respondent 1)

Therefore, educators position learners as providing scarce services, i.e. they provide rehabilitation and related AHS services when either little or no such services are available to the rural communities in uKwanda's catchment area. In doing so, learners are '... complementing the 1-month sessions that the Department of Health (DoH) is providing [via resident allied health practitioners at the rural clinical sites], but also making the DoH aware of the need for more services, or more routine services for that setting. (MDT, FGD, Respondent 3)

By means of their service, the learners develop their roles as policy brokers, e.g. OT learners who developed a risk-behaviour project focused on teenage pregnancy, substance abuse, crime and gangsterism brokered their practices with policy makers and arranged to meet with representatives from the Department of Education, the police and school educators (OT, FGD, Learner 11)

\section{Professional practices are best when delivered by team participation}

Resources were positioned as barriers and opportunities to develop practice and included challenges such as lack of physical resources and language or cultural barriers. Human resources were particularly valued by the healthcare team. Managing rehabilitation within constrained contexts allowed simultaneously focused interventions via multiple factors. This interdisciplinary approach was effective when working in teams, as noted below:

'... the different disciplines that were there .... . It was better as we could see what the physio's outlook on things was. It's not just your perspective, but a whole group of other perspectives, and how to incorporate what you do together with other's professional disciplines.' (SLT 3, FGD)

This type of professional-personal interprofessional education positively affected the quality of care, as revealed in the following quotation:

Table 3. Analysis of a student's personal journey in a rural clinical setting

\section{Student's edited reflections \\ 'Ceres is stunning and beautiful; the mountain view is something that I'm not used to, the trees with their different coloured} leaves, the fresh air, how I could just walk everywhere ... .

'I have great difficulty ... it is heart breaking to reconcile this beauty with what is on "the other side" where I witness poverty, unemployment, alcohol abuse, hurt and people who were being mistreated.'

'During my rural rotation, I see how people suffer because of poverty, some of them have jobs only for a season at a time. I spoke to members of the local community and discovered that they did not necessarily buy alcohol but made it out of fruit. All they need is sugar, fruit and some yeast and you can make alcohol from anything.'

'I wanted to understand people's lives from newborns to geriatrics. Consider what I learned about Harriet [pseudonym], who was the first baby I cup-fed, whose mother had decided to give her up for adoption - and then, perhaps as part of a process facilitated by the resident dietician, decided to keep Harriet.

'I carefully thought about how Aunty Babs, a 90-something-old woman from Kensington [Cape Town] who, after being locked up in her home by a burglar, and then unable to gain access to a service in the city, was relocated to an old persons' home in Ceres, far away from her children and family. I was inspired by Aunty Babs' ability not to let her experiences ruin her life. I identified with her relationship to God and appreciated being influenced by Aunty Babs' faith.'

'After a few weeks, I felt more settled in and at ease, and strangely enough Ceres even felt like home. I realise that dietetics was no longer just a degree that I was studying, but it became something that I was starting to enjoy and something that I could actually see myself doing in the future ... it was the first time that I really fell in love with dietetics. The whole experience taught me just to smell the roses.'

\section{Analysis}

The visibility and engagement with a physical space as critical to learning

Connecting issues of poverty and social health determinants, such as alcoholism, to healthcare

People's life histories are critical to healthcare learning

Positive, entrenched connection to the profession 
'... because the needs, and the facilities ... the resources are totally different. They require you to think differently ... . So you become more than just a speech therapist. That's what I think the students also acquire; they become more than a physio, they become a social worker, a counsellor, a psychologist, a fund-raiser. They become advocates.' (MDT, Participant 1)

\section{Professional educational curricula}

The following factors are positioned as critical curriculum issues for rural clinical training:

- context (or where learning occurs)

- educators (or who engages learning)

- time (or when or how long learners spend in training).

\section{Context}

While in a rural clinical site, learners use their disciplinary knowledge relative to broader interprofessional, cross-disciplinary learning, such as how an SLT should move or handle patients, a skill that is not part of an SLTs traditional set of skills. They reported that this form of interprofessional learning was necessary, almost 'forced', that 'with the Worcester block ... we felt that we are here and now we have to take initiative.' (SLT, FGD, Learner 5)

Indeed, learners contrasted rural experiences with metropolitan or urban hospital learning:

'... the overall goal of a hospital is to get people out as soon as possible, [you work] against time, a clock ... whereas in a community, you go in and you don't really have this entire electronic system ... . You have to see what is most needed at this stage and start there. You're building something, it's not already there for you to just use.' (SLT 8, FGD)

As explained above, the structures and regulations of urban hospital sites compete poorly with interconnected learning that occurs in rural sites. Furthermore, learners develop professional identities, a sense of professional obligation, doing what one is supposed to do '... because the needs, and the facilities ... the resources are totally different. They require you to think differently ....' (MDT, Participant 1)

Learners have recognised the multiple identities they develop owing to resource constraints, less rigid structures and the self-sufficiency they discover through their rural site experiences.

\section{Educators}

Learners realise educators '.. feel confident in the skills that we have developed ... to be able to go into this community and go and treat these patients. (OT, FGD, Learner 8)

The development of a trusting, learning relationship, the ability to manage minds in non-mainstream contexts, to focus on development and all of the skills necessary to develop rural clinical learning, constitute attributes of effective educators, as reported by participants:

'Something else that also stood out for me, compared with the urban sites, the people in Worcester want to teach you. They're very centred around getting you passionate about your field.' (MDT, Participant 8)

\section{Time}

'The knowledge and the skills that I have acquired over the past year, have taught me on an academic level, how to think, it's taught me as an individual, on a personal level, how to think as well. It's really prepared me for my community service year.' (OT, FGD, Learner 1)

A year of engagement was perceived as the optimum time for learning. Time is a factor that determines depth of learning, learner confidence, even technical skills, e.g. learners who spent clinical rotations lasting 8 weeks complained that this period was insufficient to develop skills. (SLT 8, FDG)

\section{Conclusion}

'... I think at the end they [the learners] just love it, and they're still able to put together the physio knowledge, the theory and practical skills, but somehow they come out, I don't know, human.' (MDT, FGD, Respondent 2) 'At the end of it, I was reminded once again, of the meaning of uKwanda, which is a Xhosa word that can be translated as "to grow or develop within a community, or to make a positive difference". So I was left thinking to myself whether I had had a positive influence in Ceres. I'll probably never really know, but I hope that I did.' (HN, Learner 1)

From the above educator and learner statements, it is evident that rural clinical training is undoubtedly challenging for learners and educators alike. Along with Kronenberg et al. ${ }^{[10]}$ we believe that a radical reconfiguration of the philosophical underpinnings of healthcare education must occur. For us, this reconfiguration may occur practically, by means of our curriculum, which engages people in rural communities, develops a reflective, caring healthcare practitioner, and contributes to an intrinsically humanising experience for all.

Acknowledgements. Funding was received from the Harry Crossley Foundation and the office of the deputy dean of Community Service and Interaction, Stellenbosch University.

\section{References}

1. Kautzky K, Tollman SM. A perspective on primary health care in South Africa. In: Barron P, Roma-Reardon $\mathrm{R}$ eds. South African Health Review. 13th ed. Cape Town: Health Systems Trust, 2008:17-30.

2. Jager GW. Community-based education in speech pathology and audiology at the University of DurbanWestville in an under-served community. S Afr J Commun Disord 1994;41:93-102.

3. Van Schalkwyk SC, Bezuidenhout J, Conradie HH, et al. 'Going rural': Driving change through a rural medical Van Schalkwyk SC, Bezuidenhout J, Conradie HH, et al. 'Goin
education innovation. Rural Remote Health 2014;14(2):2493.

education innovation. Rural Remote Health 2014;14(2):2493.
4. Pillay M, Kathard H, Samuel MA. The curriculum of practice: A conceptual framework for speech-language therapy Pillay M, Kathard H, Samuel MA. The curriculum of practice: A conceptual framework for speech-language the
and audiology practice with a black African first language clientele. S Afr J Commun Disord 1997;44:109-117.

5. Pillay M. (Re) habilitation and (re) positioning the powerful expert and the sick person. In: Kronenberg F Pollard N, Sakellariou D, eds. Occupational Therapies Without Borders: Towards an Ecology of OccupationBased Practices. 2nd ed. London: Churchill Livingstone, 2011:123-132.

6. Kincheloe JL. Teachers as Researchers: Qualitative Inquiry as a Path to Empowerment. London: The Falmer Press, 1991. 7. Pillay M. Do you speak practice-ese? A discourse of practice for sharing communication. Int J Lang Commun Disord 2001;36(s1):351-356. DOI:10.3109/13682820109177910

8. Burch V, Reid S. Fit for purpose? The appropriate education of health professionals in South Africa. S Afr Med J 2011;101(1):25-26. DOI:10.7196/samj.4695

9. McKenzie JA. The provision of speech, language and hearing services in a rural district of South Africa. S Afr Commun Disord 1992;39:50-54.

10. Kronenberg F, Kathard H, Rudman DL, Ramugondo E. Can post-Apartheid South Africa be enabled to humanise and heal itself? S Afr J Occup Ther 2015;45(1):20-26. DOI:10.17159/2310-3833/2015/v45nla4 